\title{
Relationship Between Heart Rate and Oxygen Uptake in Thoracic Level Paraplegics
}

\author{
Z. H. Bar-On, MD, ${ }^{1}$ A. V. Nene, MB, BS, D orth, MS (Orth), Mch Orth ${ }^{2}$ \\ ${ }^{1}$ Midlands Spinal Injuries Unit, now at Neurological Rehabilitation, Chaim Sheba \\ Medical Centre, Tel-Hashomer, Israel, ${ }^{2}$ ORLAU, The Robert Fones $\mathcal{E}$ Agnes Hunt \\ Orthopaedic Hospital, Oswestry, Shropshire, UK.
}

\section{Summary}

In able-bodied subjects heart rate and oxygen uptake have a linear relation up to submaximal workloads. Cardiac response to exercise or physical stress is described to be under the control of the sympathetic nervous system. Various workers have claimed that the sympathetic contribution to the cardiac plexus arises between thoracic spinal cord levels T1 and T6. Paraplegics are participating in various sporting activities in increasing numbers. Theoretically, assessing the progress of physical fitness of paraplegics with lesions above T6 by monitoring heart rate alone becomes unreliable because of damage to their sympathetic system.

Forty-four paraplegics with lesion levels between T3 and T10 were put through an arm cranking exercise routine with increasing power levels. Their heart rate and oxygen uptake was measured for each power level. For analytical purposes the subjects were grouped into two groups according to their lesion level. All the subjects with the lesion at T6 or above were in one group and the other group consisted of lesion at T7 or below. Almost linear relation was found between the heart rate and oxygen uptake in all subjects of both groups.

The findings of this study suggest that either the sympathetic contribution comes from above spinal level T3, or the cardiac response to an increased demand in physical exercise is controlled by some other mechanism.

Key words: Paraplegia; Ergometry; Arm-cranking; Heart rate; Oxygen uptake.

It is acknowledged that in able-bodied subjects, heart rate and oxygen uptake have a linear relation up to submaximal workloads (Astrand and Rodahl, 1977). This has simplified the task of monitoring the energy cost of a variety of physical activities by monitoring heart rate alone in an individual. This has also evolved as a common method for determining the degree of physical fitness of an able-bodied healthy individual by making him or her perform increasing workload tasks and monitoring heart rate.

Correspondence to: Dr A. V. Nene, ORLAU, The Robert Jones \& Agnes Hunt Orthopaedic Hospital, Oswestry, Shropshire SY10 7AG, UK. 
Sympathetic regulation of the cardiovascular system is claimed by various workers to be between thoracic spinal cord levels T1 and T6 (Guttmann, 1976; Silver, 1971; Lindan et al., 1980; Frankel and Mathias, 1980; Coutts et al., 1983). In the light of this knowledge, reliability of heart rate response of high thoracic level paraplegics (T6 and above) is doubtful as a means of monitoring their physical training.

ORLAU has mainly been interested in the locomotion of paraplegics. The task of comparing the energy cost of locomotion using the various forms of orthoses and of monitoring the progress of training can be made much simpler by monitoring heart rate alone.

The purpose of this study was to find out the nature of the relationship between heart rate and oxygen uptake with increasing workload in thoracic level paraplegics.

\section{Subjects}

Forty four subjects participated in the study. All were traumatic complete paraplegics. None had any associated medical problems such as pressure sores, renal disorders or cardiopulmonary disease. Their age ranged from between 15 years and 46 years. Lesion level varied from T3 to T10. It so happened that in

Table I Age distribution of subjects

\begin{tabular}{cc}
\hline $\begin{array}{c}\text { Age } \\
\text { (years) }\end{array}$ & $\begin{array}{c}\text { Number } \\
\text { of subjects }\end{array}$ \\
\hline $15-20$ & 3 \\
$21-30$ & 18 \\
$31-40$ & 13 \\
$41-50$ & 10 \\
\hline
\end{tabular}

Table II Subject distribution according to neurological level

\begin{tabular}{cc}
\hline $\begin{array}{c}\text { Neurological } \\
\text { level }\end{array}$ & $\begin{array}{c}\text { Number } \\
\text { of subjects }\end{array}$ \\
\hline T3 & 1 \\
T4 & 11 \\
T5 & 12 \\
T6 & 6 \\
T7 & 4 \\
T8 & 5 \\
T9 & 2 \\
T10 & 3 \\
\hline
\end{tabular}

our study there were 4 females and 40 males. Tables I and II show the subject distribution as regards to their age and neurological level.

All the subjects were well rehabilitated. Table III shows the subject distribution as regards to their duration of paraplegia. 
Table III Subject distribution according to duration of paraplegia

\begin{tabular}{cc}
\hline $\begin{array}{c}\text { Duration of } \\
\text { paraplegia (years) }\end{array}$ & $\begin{array}{c}\text { Number } \\
\text { of subjects }\end{array}$ \\
\hline $0-2$ & 6 \\
$2-4$ & 9 \\
$4-6$ & 6 \\
$6-8$ & 6 \\
$8-10$ & 3 \\
Over 10 & 14 \\
\hline
\end{tabular}

\section{Equipment}

1. Sport Tester ${ }^{(\mathrm{TM})}$ PE3000 by Polar Electro, Finland. IBM compatible interface and Amstrad 1640 PC. The PE3000 is a heart rate monitoring device which monitors and if instructed, records the heart rate of subjects in relation to time. An elastic belt which incorporates electrodes is attached to the subject's chest and a signal transmitter is attached. A radio frequency signal is received by the receiver within a radius of $1 \mathrm{~m}$. It can either be worn on the wrist by the subject or can be placed on the work bench. The alarm can be set for high and low limits. The heart rate can be recorded every 5 seconds or every 15 seconds.

The recorded information can be transferred to the computer memory using a computer specific interface.

Leger and Thivierge (1988) evaluated the accuracy of the apparatus by comparing the monitored values with simultaneous ECG readings. Stability as well as validity was measured using several ergometric devices and functionality was evaluated by analysing the practical aspects of the device. Their results indicate excellent correlation between readings obtained by ECG and the heart rate monitor. Prior to this study Tsanakas et al. (1986) using an earlier version of the heart rate monitor (PE2000) also showed that the 'Sport Tester' was a reliable indicator of heart rate.

2. Oxylog (Oxygen consumption meter) by P. K. Morgan Ltd., UK. This measures the oxygen consumption. The subject wears a face mask which is fitted with inspiratory and expiratory valves and a flow meter. Expired air passes through a flexible pipe connected to the instrument. The volume of oxygen extracted from the air is calculated and displayed as cumulative total volume and minute oxygen uptake.

A comment must be made regarding the accuracy of the measurements made with this apparatus. The formula used by the apparatus to calculate the volume of oxygen utilised is only correct if the respiratory quotient $(\mathrm{RQ})$ is equal to 1 . In practice under basal conditions the value of $\mathrm{RQ}$ is about 0.82 . Moderate exercise has very little effect on it (Consolazio et al., 1963). Under these circumstances the range of error in the calculated volume of oxygen uptake would be between $-1.8 \%$ to $-3.5 \%$ (Manufacturer's figures quoted in the user's manual).

3. Monark Rehabilitation Trainer. This is an arm ergometer. It was mounted on a table and secured with clamps to prevent it from moving. The table was at 
an optimum height to permit its use by people in a wheelchair, and was fixed to the wall.

4. Metronome.

5. Multi-channel ECG machine (C 3, Made by OTE Biomedica, Italy).

\section{Method}

On arrival at the Laboratory each subject was examined to confirm the neurological level of the lesion and to exclude any medical problems. The subject was weighed and had an ECG recording to exclude any obvious cardiac abnormalities. The chest band with incorporated electrodes was then fitted to the subject. The transmitter was fitted and the heart rate was monitored.

The subject then positioned him or herself in the wheelchair in front of the arm ergometer. A trial of arm cranking was given to the subject to allow familiarisation with the test procedure which required maintaining a speed of $50 \mathrm{rpm}$ facilitated by keeping time with a metronome. Whilst the subject was getting acquainted with the ergometer the Oxylog was calibrated and high-low alarm limits on the sport tester were set. The lower limit was set at 40 in all subjects and a higher limit was set according to the age (220 - age of the subject, to the nearest step of 5).

When the subject was ready the facemask of Oxylog was snugly but comfortably fitted over the face. Heart rate recording and measurement of oxygen uptake was started synchronously with the heart rate being recorded every 15 seconds.

For the first 3 minutes resting oxygen uptake and heart rate were recorded. Then the subject was asked to start arm cranking, at a steady rate of $50 \mathrm{rpm}$, at 10 watts power level. Measurements were taken for 2 minutes and then the power level was increased by 10 watts by maintaining the speed at $50 \mathrm{rpm}$ and increasing the braking torque. Again the readings were taken for 2 minutes before increasing the power level by another 10 watts. The test was continued in a similar incremental fashion until terminated because of one of the following three reasons:

(a) Arm fatigue.

(b) High heart rate alarm.

(c) Oxygen uptake reached a plateau.

After termination of the test, the subject rested in the wheelchair, and measurements of oxygen uptake and heart rate were continued until the oxygen uptake reached the pre-exercise level.

Heart rate recordings were transferred to the computer memory and then the pulse rate listing in relation to time was printed out. The average heart rate was calculated for each minute from the four readings recorded at 15 second intervals. Since the test was synchronously started it was possible to find oxygen uptake and heart rate at a given power level. Readings were taken for 2 minutes at each level. The readings of only the second minute for each power level were taken into consideration as the first minute was taken up to reach a steady revolution rate after the increase in the power level.

For each subject a set of paired readings (oxygen uptake and heart rate for each power level) was obtained. These were plotted in $\mathrm{X}-\mathrm{Y}$ graph form with the heart 
rate on $\mathrm{X}$ axis and oxygen uptake on $\mathrm{Y}$ axis. The coefficient of correlation for each set also was obtained using the statistical analysis program.

\section{Results}

Three subjects could only reach the power level of 20 watts, 12 subjects 30 watts, 9 subjects 40 watts, 15 subjects 50 watts, 4 subjects 60 watts and 1 subject could reach the power level of 80 watts.

For 2 subjects the test was discontinued because of high heart rate alarm, for another 2 the test was discontinued because they reached a plateau in their oxygen uptake (similar readings for two successive power levels). For the remaining 40 subjects the test was stopped because of fatigue of their arm muscles.

A minimum of 3 pairs of readings were available to calculate the coefficient of correlation for 3 subjects, but for the majority of the subjects 4 or more pairs of readings were available.

To facilitate the object of the study, subjects were grouped into two groups. The first group consisted of those with lesion levels between T3 and T6, and the second group consisted of those with lesion levels between T7 and T10.

Figures $1 \mathrm{~A}$ and $1 \mathrm{~B}$ show oxygen uptake and heart rate for each power level in two different groups. Both groups show increase in heart rate as well as oxygen uptake for increased power level. At higher power levels it appears that the mean values of oxygen uptake plateau out but in fact it is due to reduction in the number of subjects reaching those power levels. Obviously the subjects who managed to reach higher power levels were fitter than the rest of the group and had lower oxygen uptake values at lower power levels and it reflected in their mean oxygen uptake values at higher power levels.

Figures $2 \mathrm{~A}$ and $2 \mathrm{~B}$ show the graphs of heart rate against minute oxygen uptake for each subject in two groups. As previously mentioned, the coefficient of correlation was calculated for each set of readings. Table IV shows the mean

Table IV Coefficient of correlation of both groups of subjects

\begin{tabular}{ccc}
\hline Level of lesion & $\begin{array}{c}\text { Number } \\
\text { of subjects }\end{array}$ & $\begin{array}{c}\text { Coefficient of correlation } \\
\text { range (mean) }\end{array}$ \\
\hline T3-T6 & 30 & $0.8545-0.9992(0.9651)$ \\
T7-T10 & 14 & $0.9799-0.9991(0.9909)$ \\
\hline
\end{tabular}

correlation coefficients with their range for both groups of subjects. In both groups subjects showed an almost linear relationship between the heart rate and oxygen uptake. The coefficient of correlation for each whole group was also calculated. The regression line with $95 \%$ prediction limits for the entire group are represented as a broken line in Figures 2A and 2B. Almost all of the subjects' plots fall between the $95 \%$ prediction limits. For the group with lesion levels between T3 and T6 the coefficient of correlation was $0 \cdot 7824$ and for lesion levels between T7 and T10 it was 0.8592 . In the first group there were 154 pairs of readings and in the second group there were 75 pairs of readings. The t-test was applied to these $R$ values. Both were found to be very highly significant $(P<0.001)$. 


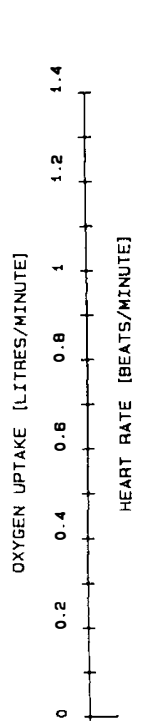

$$
\text { T3 - TG }
$$

- MAX.
0 - MEAN
X - MIN.

- MAX.
$0-$ MEAN
X - MIN.

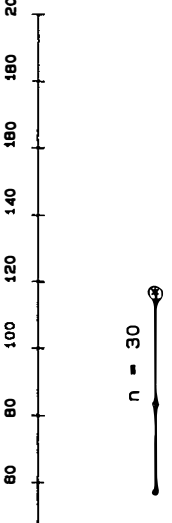

T)
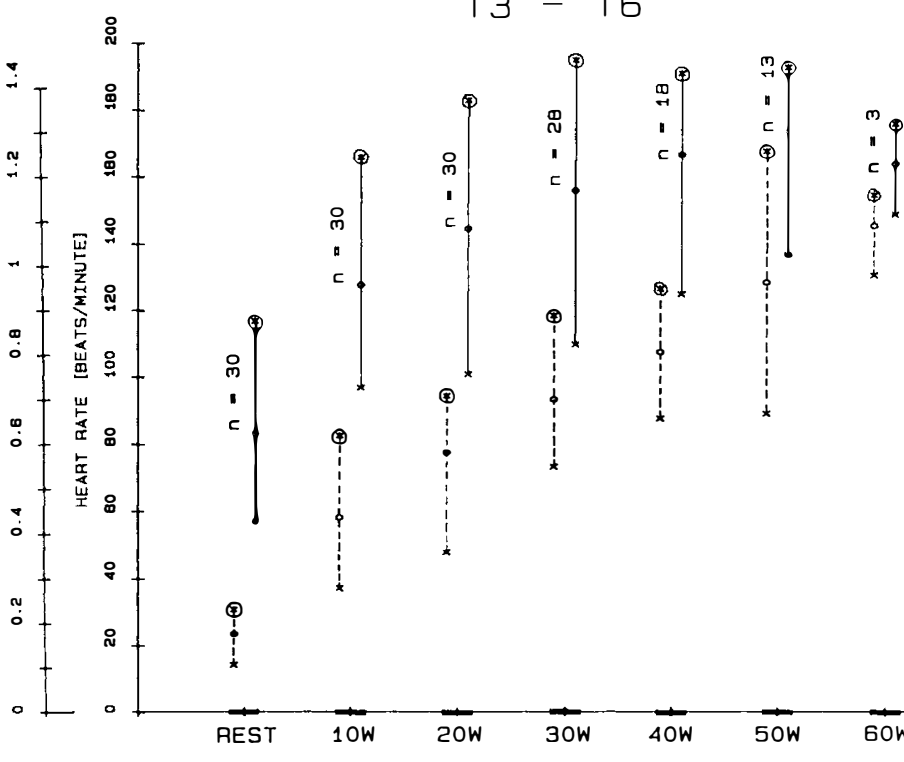

POWER LEVEL

OXYGEN UPTAKE ------

HEART RATE

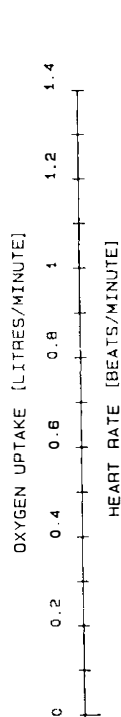

T7 - T10

$\circ+$

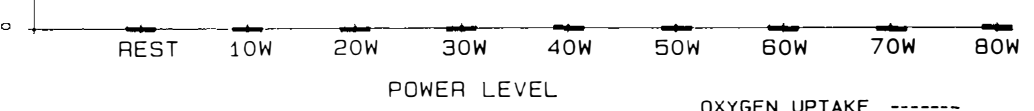

OXYGEN UPTAKE

HEART RATE

Figure 1 Oxygen uptake and heart rate for each power level for the two groups of subjects.

\section{Discussion}

In the able-bodied subjects heart rate and oxygen uptake have a linear relation up to submaximal workloads. It is generally observed that the heart rate of tetraplegic subjects is not increased in response to a variety of systemic pathological factors as 
HEART RATE AND WORKLOAD IN THORACIC LEVEL PARAPLEGICS 93
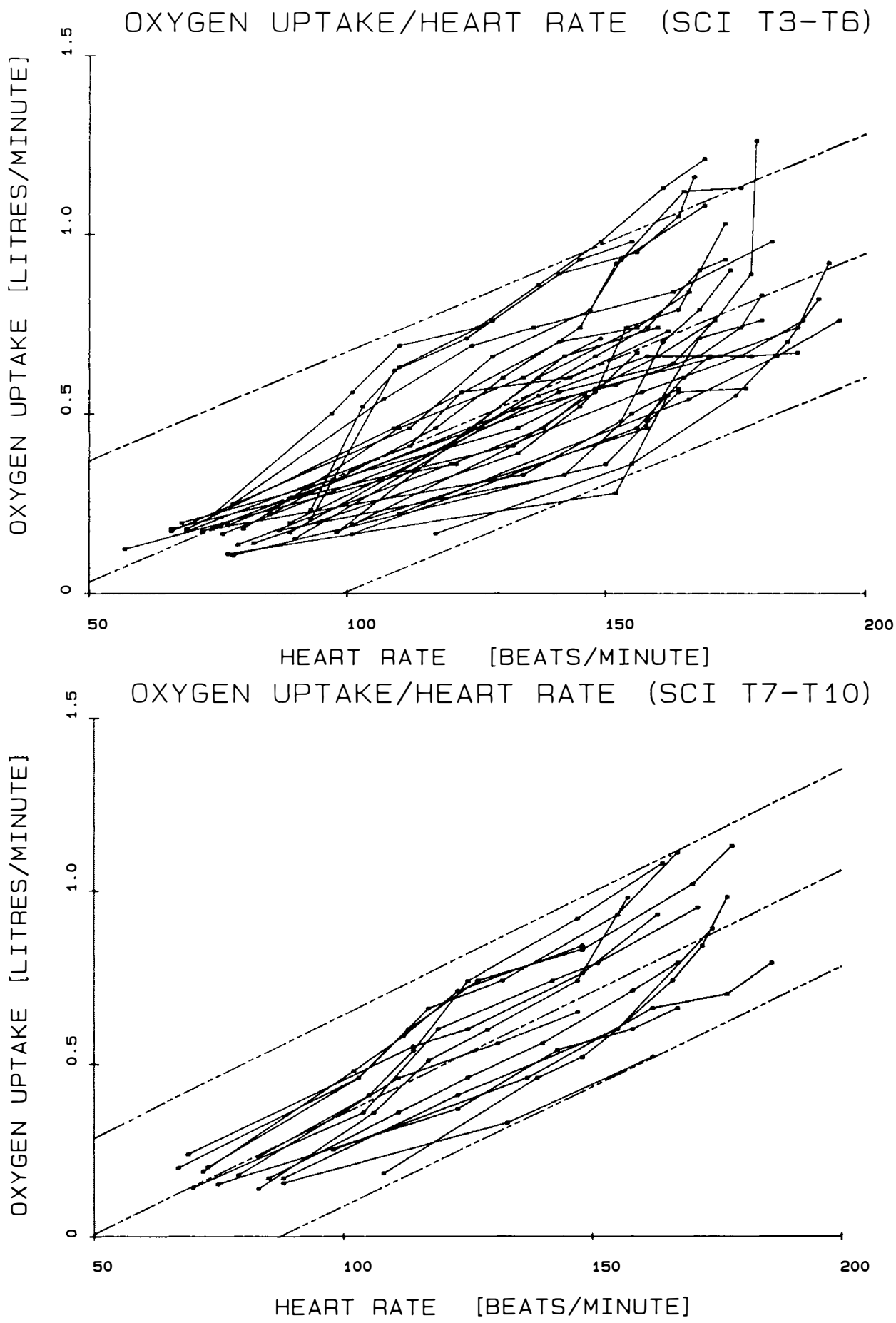

Figure 2 Graphs of oxygen uptake against heart rate in two groups of subjects (Broken lines indicate regression line and $95 \%$ prediction limits). 
it occurs in able-bodied individuals. It is well documented that in tetraplegic individuals there is a block of the sympathetic medullary efferents and a syndrome of autonomic hyperreflexia has been well described in tetraplegics and high thoracic lesion paraplegics (Head and Riddoch, 1917; Guttmann, 1947; Silver, 1971).

In many textbooks of anatomy and physiology the sympathetic contribution to the cardiac plexus is mentioned to be somewhere between T1 and T6. This study shows that subjects with complete SCI below the level of T3 reveal a linear relationship between the heart rate and oxygen consumption with increasing power levels. This indicates that the sympathetic outflow is intact in these subjects. It is difficult to infer with only one subject with a lesion level at T3 whether the linear relation exists or not at $\mathrm{T} 3$.

Other evidence in support of an intact sympathetic outflow below T3 is the subjects' ability to attain very high heart rates. Knutsson et al. (1973) suggested that in complete cervical cord transection the heart rate regulation is attained by varying vagal tone. This implied that the heart rate increase in these patients is restricted up to levels just above 100 beats per minute. Subjects in the present study attained much higher values than that.

This may suggest that the sympathetic contribution arises above spinal level T3. Another possibility could be that the cardiac response to an increased demand in the physical exercise state is controlled by some other mechanism.

Monitoring of progress in physical training is made easier in the able-bodied due to the fact that oxygen uptake and heart rate are linearly related to one another. The results of the present study show that in patients with a SCI below the level of T3, a similar relationship exists. Physical rehabilitation training of paraplegics could be monitored by measuring their heart rate after various activities at regular intervals. Lower heart rates for the same activities in an individual will indicate a better physical fitness status.

With greater social awareness of the needs of physical activity for physically handicapped persons, more and more sporting facilities are made available to these people. Large number of physically handicapped people are taking up athletic training. Their progress can be reliably monitored by measuring heart rate alone as it is for able-bodied athletes.

This method of measurement of heart rate can also be extended to walking rehabilitation of paraplegics. Physiological cost index was shown to be an indicator of energy cost of locomotion (Butler et al., 1984). As an indication of locomotor efficiency, physiological cost index is based on the method described by MacGregor (1979). This states that:

$$
\begin{aligned}
& \text { Physiological Cost Index } \\
& \text { (PCI) }
\end{aligned}
$$

where $\mathrm{Hw}$ (beats/minute) $=$ Heart rate while walking (averaged from the heart rate at the end of each $25 \mathrm{~m}$ walk)

$\mathrm{Hr}$ (beats/minute $)=$ Heart rate at rest

$\mathrm{S}(\mathrm{m} / \mathrm{minute})=$ Average Speed.

An individual under training can be assessed and his or her PCI calculated periodically, or the performance of various orthoses can be compared in an 
individual by measuring PCI for each orthosis. In larger groups of subjects, the range of PCI can be compared for different groups.

\section{Conclusion}

The findings of this study suggests that the sympathetic contribution to the cardiac plexus is intact in traumatic complete paraplegics with a lesion level below T3 as evidenced by the linear relation between their heart rate and oxygen uptake with increasing work loads. Another possibility could be that the cardiac response to an increased demand in the physical exercise state is controlled by some other mechanism. Further studies will be required to elucidate this.

\section{Acknowledgements}

The authors are sincerely grateful for Mr W. S. El Masri, FRCS, Director, Midlands Spinal Injuries Unit for allowing them to study patients from the Unit as subjects. Authors also sincerely thank $\mathrm{Mr}$ M. McClelland, FRCS, for his constructive suggestions, and Miss C. A. Morris for her secretarial help in preparing this manuscript.

\section{References}

Astrand PO, Rodhal K 1977 Textbook of Work Physiology. McGraw Hill, New York.

Butler P, Engelbrecht M, Major RE, Tait JH, Stallard J, Patrick JH 1984 Physiological cost index of walking for normal children and its use as an indicator of physical handicap. Developmental Medicine $\mathcal{E}$ Child Neurology 26: 607-612.

Consolazio, et al. 1963 Physiological Measurements of Metabolic Functions in Man. McGraw Hill, New York, p 315.

Coutts KD, Rhodes EC, MCKenZIE DC 1983 Maximal exercise responses of tetraplegics and paraplegics. Fournal of Applied Physiology 55:479-482.

FRANKEL HL, Mathias CJ 1980 Severe hypertension in patients with high spinal cord lesions undergoing electro-ejaculation management with prostaglandin E2. Paraplegia 18:293-299.

GutTMANN L 1976 Spinal Cord Injuries. Comprehensive Management and Research, 2nd edn. Blackwell Scientific, Oxford.

GUTTMANN L, WHITTERIDGE D 1947 Effects of bladder distension on automatic mechanisms after spinal cord injury. Brain 70:361-404.

HEAD H, RIDDOCH G 1917 The automatic bladder, excessive sweating and some other reflex conditions in gross injuries of the spinal cord. Brain 40:188-263.

Knutsson E, Lewenhaupt-Olsen E, ThORSEn M 1973 Physical work capacity and physical conditioning in paraplegic patients. Paraplegia 11:205-216.

Leger L, ThIVIERge M 1988 Heart rate monitors: Validity, stability and functionality. The Physician and Sports Medicine 16:143-151.

LindAN R, JoINER EA, FreEhAFER AA, HAZEl C 1980 Incidence and clinical features of autonomic dysreflexia in patients with spinal cord injury. Paraplegia 18:285-292.

MACGREgor J 1979 The Objective Measurements of Physical Performance with Long-Term Ambulatory Surveillance Equipment (L.A.P.S.E.). In: STOTT FD, RAFTERY EB, Goulding L (eds) Proceedings of 3rd International Symposium on Ambulator Monitoring. Academic Press, London, pp 29-39.

Oxylog Instruction Manual, P.K. Morgan Ltd.

SILVER JR 1971 Vascular reflexes in spinal shock. Paraplegia 8:231-242.

TSANAKas JN, BanNister OM, BoON AW, Milner RDG 1986 The 'Sport Tester': a device for monitoring the free running test. Archives of Disease in Childhood 61:912-914. 